\title{
A confirmatory composite analysis for the Italian validation of the interactions anxiousness scale: a higher-order version
}

\author{
Enrico Ciavolino ${ }^{1,3}$ (D) - Lucrezia Ferrante ${ }^{1}$. Giovanna Alessia Sternativo ${ }^{1}$. \\ Jun-Hwa Cheah ${ }^{2} \cdot$ Simone Rollo $^{1} \cdot$ Tiziana Marinaci $^{1} \cdot$ Claudia Venuleo $^{1}$
}

Received: 3 May 2021 / Accepted: 6 September 2021 / Published online: 2 October 2021

(c) The Author(s) 2021

\begin{abstract}
This study examined the factor structure and model specifications of the Interaction Anxiousness Scale (IAS) with confirmatory composite analysis (CCA) using partial least squares-structural equation modeling (PLS-SEM) with a sample of Italian adolescents $(n=764)$. The CCA and PLS-SEM results identified the reflective nature of the IAS sub-scale scores, supporting an alternative measurement model of the IAS scores as a second-order reflective-reflective model.
\end{abstract}

Keywords Interactions Anxiousness Scale · Partial least squares · Confirmatory composite analysis $\cdot$ Structural equation model $\cdot$ Higher-order $\cdot$ Adolescents

\section{Introduction}

Social anxiety is defined as "a state of anxiety resulting from the prospect or presence of interpersonal evaluation in real or imagined social settings" (Leary and Schlenker 1981). Although it is usually associated with specific behavioural manifestations in social interactions, such as avoidance, hesitancy and awkwardness, it should be intended as a merely subjective experience, independent from specific overt behaviours (Leary 1983): indeed, the presence of individual anxiety is not necessarily accompanied by the other, so that people who are able to manage and hide their anxiety could behave competently, and, conversely, people who show avoidant, hesitant, or awkward behaviours could not report social anxiety. At the basis of social anxiety (or sometimes known as social anxiousness) there is a concern with the others' perceptions and evaluations at the moment of an

Communicated by Marko Sarstedt and Heungsun Hwang.

Enrico Ciavolino

enrico.ciavolino@unisalento.it

Extended author information available on the last page of the article 
interaction or/and at the prospect of participating in a particular encounter, across different social situations and time.

Starting from this premises, Leary (1983) has developed an instrument, namely "Interactions Anxiousness Scale (IAS)", which aims to measure subjective anxiousness in specific social situations, by investigating the individual's tendency to feel nervous in social encounters, independently of patterns of inhibited, reticent, or avoidant behaviour. Hence, IAS considers only the affective component of social discomfort (Leary and Kowalski 1993), differently from other instruments which in turn focus on cognitive aspects of the phenomenon, such as the "Fear of Negative Evaluation Scale" (Watson and Friend 1969) and the "Social Interaction Self-statement Test" (Glass et al. 1982), or both affective and behavioural facets, such as the "Social Avoidance and Distress Scale" (Watson and Friend 1969) and Liebowitz Social Anxiety Scale (Liebowitz 1987).

The IAS is composed by 15 items referring to subjective affective reactions to social situations, such as feeling "anxious," "nervous," and "tense", whereas there are no mentions to specific social behaviours, such as avoidance of interactions, a hesitancy to speak to others, etc. Respondents indicate how much the experience described in the sentence is characteristic of them when they interact with other people. The IAS seems to represent a valid instrument to measure the presence of social anxiousness among youths across different interactions scenarios. For instance, having a conversation with a person of the opposite sex, meeting new people in a party or talking with authority figures (e.g. teachers), all situations which seems to be near to adolescents' social experience.

The instrument revealed a one-factor structure in its final 15-items version developed among American university students (Leary 1983). Leary and Kowalski (1993) have collected extensive data on the psychometric properties of the scale, revealing a high test-retest and internal reliability (respectively of 0.80 and 0.85 ) as well as good construct and criterion-related validity. More specifically, IAS showed high correlations with other measures of social anxiety, inhibition, and shyness, such as the SAD Scale (Watson and Friend 1969), the Shyness Scale (Cheek and Buss 1981), the Social Anxiety subscale of the Self-Consciousness Scale (Fenigstein et al. 1975), moderate (range $=0.35-0.50$ ) with measures of specific subtypes of social anxiety (e.g., physique anxiety, embarrassability), as well as general anxiety (e.g., neuroticism, trait anxiety), and low $(r=-0.26)$ with Marlowe-Crowne Social Desirability Scale (Crowne and Marlowe 1964), giving some evidences of discriminant validity (Leary 2013).

Respect to the European context, a study conducted with Spanish university students (Sanz 1994) on IAS psychometrics proprieties found high reliability (Cronbach $\alpha=0.90)$, high and positive correlation with the SAD scale $(r=0.76)$, and an acceptable discriminant validity with respect to depression measured by the Beck Depression Inventory (Beck et al. 1996) $(r=0.43)$. In the same Spanish study, data concerning factorial validity for the IAS consistently indicate either the existence of only one factor or the existence of two highly related factors: a large general social anxiousness factor on which most of the items would load, and a small factor on which items related to interaction with authority figures, as emerged also in a study among American university students (Leary and Kowalski 1986). 
A study conducted among Turkish adolescents (Subasi 2013) with a 21-items version of the IAS adapted to Turkish young population by Subasi (2007) revealed a high internal consistency (Cronbach $\alpha=0.86$ ) and a high split-half reliability (Spearman-Brown and Guttman's reliability coefficients were also calculated and found to be .85 for both). For the construct validity of scale, a factor analysis was run, and it was observed that the scale revealed a unidimensional solution. Unfortunately, there is not an Italian validation of IAS, although some studies employ the instrument, especially among young people (Contardi et al. 2013; De Berardis et al. 2007). In the Italian context, instruments for the investigation of social anxiety among adolescents in turn focus on shyness ("Children's Shyness Questionnaire" ; Spensieri et al. 2019), appearance anxiety ("Social Appearance Anxiety" ; Dakanalis et al. 2016) and social phobia ("Social Anxiety Questionnaire for Children" ; Caballo et al. 2012; "Social Phobia and Anxiety Inventory for Children" ; Ogliari et al. 2011); to date, no instrument specifically investigate on the adolescent's social anxiety by recalling what he/she feels in different social interactions. Yet, interacting with peers, authorities, strangers, and the opposite sex are all scenarios which require to manage the impression on others, a matter of great concern during the adolescence more than in other periods (Johnson et al. 2011); furthermore, the individual's self-image_-strictly connected to social anxiety (Di Blasi et al. 2015)—includes also perceptions about one's own social attitudes (Offer et al. 1989) which organize the functioning in various social domains, which are specifically investigated by the IAT.

Having an instrument of social anxiety addressed to young people seems very important in the field of mental health. Adolescence is known to be a period of great changes in the social sphere, with an increasingly openness to the world of peers, to whom they become more reliant (Larson and Richards 1994); unsurprisingly, social anxiety may climb with the transition to this period of life, as reported in several empirical studies (Costello et al. 2003; Michiel Westenberg et al. 2004; Wittchen et al. 1999). In the social context of peers, where they spend more time, exercise their social skills, and have new experiences in intimacy and sexuality (Buhrmester and Furman 1987; Larson and Richards 1994), adolescents face with strong desires for personal validation and consequently with the fear of negative evaluation and rejection (Harter et al. 1996; Leigh and Clark 2018; McElhaney et al. 2008). Adolescents high in social anxiety may in turn manifest other problems, such as depression (Beesdo et al. 2007; Stein et al. 2001), suicide (Davidson et al. 2011; Gallagher et al. 2014), substance abuse (Buckner et al. 2008, 2007), problematic internet use (Caplan 2006; Lee and Stapinski 2012; Venuleo et al. 2020), poor school performance (Mazzone et al. 2007; Van Ameringen et al. 2003).

The present study addresses the following objective:

1. to examined the factor structure and model specifications of the Interaction Anxiousness Scale (IAS) with confirmatory composite analysis (CCA) PLS approach, that is to evaluate the presence of eventual sub-scales specific of Italian adolescents; 
2. to test the measurement model of IAS with Italian adolescents using a higherorder modeling, that is modeling the concept of social anxiousness on a more abstract dimension (referred as higher-order component) and its more concrete sub-dimensions (i.e. lower-order components) linked by reflective relationships.

\section{Method: data analysis}

The scale has evaluated following a two stages of analysis: The first stage is an explorative analysis, aimed at investigate the latent structure underlying the IAS scale to evaluate the presence of eventual sub-scales specific of the sample analysed; in the second stage, the sub-scales identified will be confirmed by using a new/ recent method called CCA based on PLS-PM. As suggested by Hair et al. (2019), the two stages are performed by randomly dividing the sample in two sub-samples of 382 units each: A training sample where the explorative analysis is executed; a test sample where the CCA is conducted for the confirmatory purpose. In the following sub-sections an in deep focus on the methodologies and their use will be illustrated.

\subsection{Explorative analysis (PCA)}

To ascertain the number of dimensions contained in the IAS scale, data were subjected to a principal component analysis (PCA), a multivariate analysis technique aimed to explain the variability of a phenomenon in a way that preserves as much 'variability' (i.e. statistical information) as possible, that is, reducing the dimensionality of a dataset with observations on $\mathrm{p}$ numerical variables, using a q number of components so that $q<p$ (Jolliffe and Cadima 2016). This analysis was run on $\mathrm{R}$ software. Before executing the confirmative analysis with CCA, PCA was used for exploring the theoretical and latent structure of the scale, in way to highlight sub-scales in the IAS. More specifically, a sequence of analyses was performed on the whole items, considering orthogonal rotations, in way to select and remove the groups of items with high saturation coefficients, with the aim to identify new latent constructs (sub-scales), according to a theoretical background.

\subsection{Confirmatory composite analysis for higher-order modelling with PLS}

To confirm the factorial structure a partial least squares-path model (PLS-PM) with higher-order construct has been implemented and evaluated by using a confirmatory composite analysis (CCA) trough SmartPLS and R software. CCA can be seen as an emergent and systematic method/process for confirming the measurement model in the partial least squares framework for the structural equation modelling (Hair et al. 2019; Henseler et al. 2016; Hair et al. 2019; Schuberth et al. 2018). 


\subsubsection{The higher order modelling}

The IAS has been conceptualized as a second order latent variable based on the explorative analysis made in the first step. The advantage of higher-order construct (HOC) can be seen from both theoretical and empirical considerations (Cheah et al. 2019; Sarstedt et al. 2019; Ciavolino and Nitti 2013a, b).

A higher-order construct allows researchers to be able to model a concept on a more abstract dimension (referred to as a higher-order component) and its more concrete sub-dimensions (i.e. lower-order components).

Moreover, by using a higher-order construct, it able to obtain parsimony in a model because the modelling helps to reduce the number of relations of the path model (Johnson et al. 2011; Polites et al. 2012). In other words, it helps to overcome the bandwidth-fidelity dilemma (Cronbach and Gleser 1957) and it can deal with multicollinearity matter, especially for the case of formative indicators (Hair et al. 2018).

Higher-order models can be estimated by using MLE and PLS methods, but they are usually referred to the PLS framework under the name of hierarchical component models, especially for the various procedures to define the hierarchical structure (repeated indicators, two stage, hybrid) in the variables and the methods to define the relationships between higher and lower order variables (reflective and formative, see Cheah et al. 2019; Sarstedt et al. 2019).

Wold's original design of PLS path modelling does not consider higher-order latent variables, but in the last years several approaches has been proposed to estimate Higher-Order Latent Variables in PLS-SEM: (1) the repeated indicator approach and the extended version (Wold 1982; Lohmöller 1998; Becker et al. 2012; 2) the sequential latent variable score method or two-stage approach (Becker et al. 2012; Nitti and Ciavolino 2014; Wetzels et al. 2009; Ringle et al. 2012); (3) the hybrid approach (Bradley and Henseler 2007) and (4) the recent approach aimed at using Mode A consistent (or PLSc) estimation that assess HCM as composites of common factors (Van Riel et al. 2017).

\subsubsection{Measurement model: why reflective-reflective (Type I)?}

The use of a higher order constructs implies that researchers must ensure that the measurement theory is well developed and the higher-order construct's conceptualization and specification must be based on this. In the literature there are four types of HOCs (Becker et al. 2012; Cheah et al. 2019; Ringle et al. 2012):

1. reflective-reflective, that implies a type of reflective relationship between the HOC and the lower order constructs (LOCs) and where the latter are also measured in a reflective way;

2. reflective-formative, where the HOC represents a more general construct of the reflectively measured LOCs. The specific LOCs do not necessarily share a common cause but rather form the general HOC. This model is employed when a modification in one dimension does not necessarily imply a modification in 
another, so they do not necessarily co-vary. Rather, each dimension can vary independently of the others (Barroso and Picón 2012);

3. formative-reflective, that includes a more general HOC that explains the formatively measured LOCs. As goal there is the extracting of the common part of formatively measured LOCs, that represent the same theoretical content. However, every LOC builds on a set of different indicators.

4. formative-formative, an HCM that determines the relative contribution of the formatively measured LOCs to the more abstract HOC. The purpose of this model is to structure a complex formative construct with many indicators into several sub-constructs, as is the case when researchers subsume several concrete aspects under a more general concept.

In our contribution, the choice of the reflective-reflective model implies a type of reflective relationship between the HOC (IAS) and the LOCs (based on the results of the PCA Analysis), where the latter are also measured in a reflective way. The graphical representation of the reflective-reflective model is conceived with arrows/relationships start from the HOCs reaching the LOCs and then, with arrows from the LOCs to the MVs (items).

The reason that makes the choice of the reflective-reflective model appropriate lies in the high correlation of the LOCs, in which the HOC is the common factor of many other specific lower factors (LOCs), and the main objective of this study is to derive distinct reflective LOCs (Becker et al. 2012; Lohmöller 1998) having an $\mathrm{HOC}$ as common factor.

The decision of the reflective-reflective model is also supported by the (soft) psychological theory at the base (analyzed in deep by the PCA in the first step) since it is the presence of a certain level of anxiety in the adolescent's social interactions that gives rise to discomfort and sense of inadequacy in interactions, nervousness when interacting with authority figures, discomfort in unstructured interactions or to comfortability in interaction with unknown-the latter when such level is lower.

\subsubsection{Estimation methods}

Two main approaches in estimating SEM parameters have raised two important issues: the first concerns the parametric approach, with the maximum likelihood estimation (MLE) method developed by Jöreskog (1970); the second one concerns a nonparametric approach, namely partial least squares (PLS) by Wold (1975). In the last years also some news estimation approaches have been proposed and used in literature as the generalized structured component analysis (Hwang and Takane 2004) and the generalized maximum entropy (GME) as semi-parametric approach (Ciavolino and Al-Nasser 2009; Ciavolino and Dahlgaard 2009; Carpita and Ciavolino 2017).

For a sake of simplicity here we give a little introduction to MLE and PLS that represent the two mainstream methods and in deep discussed from theoretical and applied point of view, with the aim to motive the choice of PLS approach. The parametric approach MLE (Jöreskog 1970) also known as covariance-based SEM has 
been conceptualized as the hard modeling with distribution assumptions, big sample size and some limits in the specification of formative indicators. The non-parametric approach PLS also known as component based SEM, PLS-SEM or PLS-PM, has been proposed by Wold (1975) and defined as soft modeling and in contrast with MLE do not require distributional assumptions, there are no identification problem, it works with small sample size and it is easy to define reflective and formative items. Research has gradually led to the shift from targeted and simple models to more complex models (Sharma et al. 2019) with higher-order constructs (Sarstedt et al. 2019) and this transition is also mainly due to the greater diffusion of PLS estimator in the SEM framework.

In this this study, PLS approach was used because it avoids hypotheses on data distribution (see Sect. 3.1) and sample size and not tests the model by evaluating discrepancies between empirical and implicit covariances of the model (Hair et al. 2016, 2017; Vinzi et al. 2010; Rigdon et al. 2017). Moreover, PLS-SEM can determine unique score for the constructs (Rigdon 2016), so it is more appropriate for scale development and assessment. Finally, PLS-SEM does not require an underlying theoretical model before data collection, unlike CB-SEM.

\subsubsection{Confirmatory composite analysis}

A recent method for confirming and evaluating the measurement models in PLSSEM is the so called CCA (Henseler et al. 2014). This approach can be seen as a non-parametric version of the confirmative factorial analysis with the adoption of the terminology "composites" (Rigdon 2014) to make clearer PLS-SEM applications and terminology.

The statistical objective of CCA is the confirmation of a measurement theory and begin with proposing theoretical constructs to be confirmed (Hair et al. 2020).

To assess the higher-order measurement model a two-stage process has to be followed as showed in the Fig. 1: in the first stage, the lower order measurement model is assessed considering the standard steps; in the second stage the HOC is assessed by considering as items the LOCs leaving out the repeated items.

The Fig. 1 is specific for the presented case study and therefore for the reflectivereflective measurement model, but it can be generalized for the four types of HOCs (Becker et al. 2012; Cheah et al. 2019; Ringle et al. 2012) as specified above. Below there are the steps should be followed to execute a CCA with reflective-reflective measurement models split in two stages defined above:

Stage 1: LOC measurement model assessment:

- (1) The first step to follow is the assessment of the indicator loadings and their significance, obtaining a value between 0.40 and 0.708 for the standardized loadings (Hulland 1999). Through bootstrapping procedure (Hair et al. 2012) associated t-statistic should be above \pm 1.96 to be significant for a two-tailed test at the $5 \%$ level (Hair et al. 2012);

- (2) The second step regarding the indicators reliability (items), that is the quantity of the amount of variance, shared between the individual indicator variable 


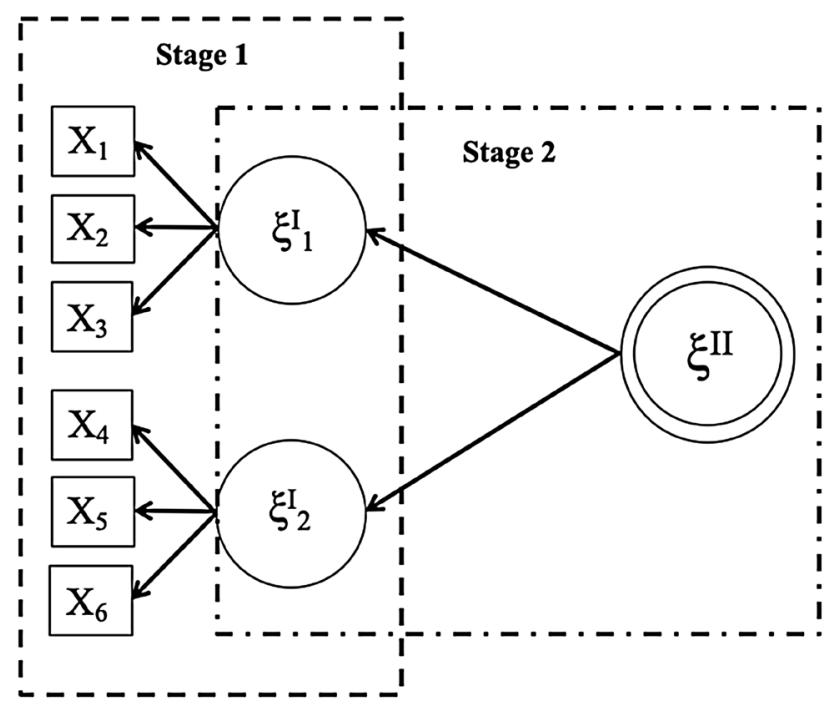

Stage 1: Assessment of Lower Order Measurement Model

Stage 2: Assessment of Higher Order Measurement Model

Fig. 1 CCA assessment stages for higher-order model

and its associated construct, is provided by squared individual indicator loadings (Hair et al. 2019);

- (3) In the third step for the composite reliability (construct) assessment the two reliability criteria Cronbach's alpha $(\alpha)$ and composite reliability $(\mathrm{CR})$ can be employed and both need a value above 0.70. The unweighted Cronbach's alpha is more precise than composite reliability (that is weighted), because indicators are not equally reliable;

- (4) In the fourth step convergent validity is measured by the average variance extracted (AVE), obtained by averaging the indicator reliabilities of a construct, which value must be equal to/exceed the 0.50 threshold;

- (5) Discriminant validity was assessed using three criteria including crossloadings, Forner-Lacker criterion (Fornell and Larcker 1981), and heterotraitmonotrait (HTMT) as suggested by Henseler et al. (2015), Hair et al. (2017). The first method provides that the outer loading of an item should be greater on its respective latent variable than its cross-loadings on other latent variables. According to Forner-Lacker criterion, the square root of AVE, of each of the latent variable, should be greater than its correlation with other latent variables. In the end, HTMT approach can be seen as an estimation of the inter-construct correlation (Nunnally 1978; Netemeyer et al. 2003), that in case has a value close to 1 shows a non-discrimination between constructs. HTMT can be used as criterion, with a thresholds of 0.85 (Kline 2011; Clark and Watson 2016) and 0.90 (Gold et al. 2001; Teo et al. 2008), or as bootstrap statistical test (HTMT_inference), defining confidence intervals: if the value one is contained in $\mathrm{CI}$, the two components are not empirically distinct, while if one is outside of the intervals, 
this suggests no discriminant validity problems. (Shaffer 1995; Henseler et al. 2015).

\section{Stage 2: HOC measurement model assessment:}

- (1) Reliability: the composite reliability is defined as:

$$
\rho_{\mathrm{c}}=\frac{\left(\sum_{k=i}^{p} l_{i}\right)^{2}}{\left(\sum_{k=i}^{p} l_{i}\right)^{2}+\sum_{k=i}^{p} \operatorname{var}(e)_{i}}
$$

where $p$ is the number of LOCs, $(e)_{i}$ and $\operatorname{var}(e)_{i}$ are respectively the measurement error and its variance of the $i$ th LOC, (note that $(e)_{i}=1-l_{i}^{2}$ ). Since the repeated indicator is estimated by the using a standard PLS-SEM approach, the estimated $l_{I}$ coincides with the estimated path coefficients between HOC and LOCs. The Cronbach's alpha is defined as follow:

$$
\alpha=\frac{p \cdot \bar{r}}{1+(p-1) \cdot \bar{r}}
$$

where $\bar{r}$ is the average of the correlations between the LOCs.

- (2) Convergent validity: assessed by the AVE index, is the average of the HOC's squared loadings $l_{i}^{2}$ (squared beta coefficients) between HOC and LOCs:

$$
\mathrm{AVE}=\frac{\sum_{k=i}^{p} l_{i}^{2}}{p}
$$

- (3) Discriminant validity is based on the same criteria defined above for the LOCs: cross-loadings, Forner-Lacker and HTMT. In the HOC measurement model the assessment of discriminant validity has to be performed by considering components in a nomological/legal network, that means the HOC has to be linked to any other exogenous or endogenous variable. In our specific case study, the HOC is specified as a stand-alone component, so it does not make sense to evaluate the discriminant validity.

- (4) Assessing the LOCs loadings and their significance: In the second stage it is important to remember that also the statistical significance has to be evaluated by bootstrap method.

\section{Results}

\subsection{Sample description}

The dataset used in this study was obtained from a larger web-based survey on adolescents' well-being and risk behaviors. The study was performed in public high schools situated in the Southern Italy with a total of 764 high school pupils attending year $9(52 \%)$ and $11(48 \%)$ and aged from 13 to 19 (mean age $=15.05 \pm 1.152)$, among whom $46.9 \%$ were female. 
Written parental consent was required through the participating schools some days before the administration; the students have filled the questionnaire on their classroom PCs using Google Forms. It was outlined the voluntary nature of the participation and the anonymity of the responses and encouraged questions for any doubts and needs of clarification. The socio-demographic characteristics of the sample, disaggregated for gender, are shown in Table 1 no significant differences related to gender have been found.

Moreover, the Shapiro-Wilk's test is performed per each IAS variable and all the items showed a $p$ value $<0.05$, implying that the sample is significantly different from normal distribution. Multivariate normality was not performed because univariate normality is a condition needed to evaluate for it (Mvududu and Sink 2013).

\subsection{Instrument and procedures}

The Interaction Anxiousness Scale (IAS; Leary 1983) is a self-report questionnaire composed by 15 items and scores on 5 points Likert (from $1=$ "Not at all" to $5=$ "Extremely"). Item 8 was adapted to the age of the sample, therefore changed from "I would be nervous if I was being interviewed for a job" to "I would be nervous if I had an oral test". The total score is obtained by summing the responses to each items, after reversing the items 2, 3, 6, 10 and 15. IAS scores ranges from 15 to 75 , with high scores indicating a high level of social anxiety in interactional situations. In the present study, the Italian translation of the instrument was developed through a back-translation method (see Appendix).

\subsection{PCA results}

A sequence of three PCAs, considering orthogonal rotations, was performed on the training sample $(n=382)$ considering all the items of IAS construct: in each PCA, when a group of items saturated on a component and this set of indicators made sense with respect to the psychological theory, these indicators were removed and the number of components decreased by one. Below the results of every PCAs, with the relative items and the eigenvalues:

Table 1 Socio-demographic characteristics of the sample

\begin{tabular}{lllll}
\hline & Male $(\%)$ & Female $(\%)$ & Total $(\%)$ & Chi-square \\
\hline Age & & & & \\
$13-15$ & 54.1 & 45.9 & 427 & 0.356 \\
$16-19$ & 51.9 & 48.1 & 337 & \\
Class & & & & \\
Year 9 & 53.4 & 64.6 & 397 & 0.022 \\
Year 11 & 52.9 & 47.1 & 367 & \\
\hline
\end{tabular}


- First PCA with four components fixed, the results confirm the presence of a component on which items 2,3 and 15 saturate (first eigenvalue $=3.561$; second eigenvalue $=1.443$;

- Second PCA having 3 components fixed, the items 9, 11, 12 and 13 saturate on the same factor (first eigenvalue $=3.414$; second eigenvalue $=1.066$ )

- Third PCA it reveals another a component on which item 8, 4 and 14 saturate (first eigenvalue $=2.106$; second eigenvalue $=0.934$ ) and another component on which the remaining item 1,5 and 7 saturate.

These analyses revealed a four-factor solution. Table 2 reports the correlations between the items and the four components: (1) Component 1: item 2, item 3, item $15\left(\xi_{\text {IAS } 1}^{I}\right)$; (2) Component 2: item 9, item 11, item 12, item $13\left(\xi_{\text {IAS2 }}^{I}\right)$; (3) Component 3: item 4, item 8, item $14\left(\xi_{\text {IAS3 }}^{I}\right)$; (4) Component 4: item 1, item 5, item 7 ( $\xi_{\text {IAS4 }}^{I}$ ).

The formalization of the theoretical model is defined by the path diagram reported in the following Fig. 2.

Table 3 shows the main descriptive statistics on the whole sample (mean, SD mean, SD, skewness, SE skewness, kurtosis and SE kurtosis) for all items. In the first column, the main component on which each MV saturates (i.e. a summary of the PCAs performed).

The first factor $\left(\xi_{\mathrm{IAS} 1}^{I}\right)$ consists of items (i.e. positively worded items, to be reversed) referring to Comfortability in interactions with unknown other; the second $\left(\xi_{\mathrm{IAS} 2}^{I}\right)$ to discomfort and sense of inadequacy in interactions; the third $\left(\xi_{\mathrm{IAS} 3}^{I}\right)$ to Nervousness in interactions with authority; the forth $\left(\xi_{\mathrm{IAS} 4}^{I}\right)$ to discomfort in unstructured interactions.

Table 2 Saturation matrix

\begin{tabular}{lllll}
\hline & PCA 1 & PCA 2 & PCA 3 & \\
\hline Items & 1 & 2 & 3 & 4 \\
IAS2R & 0.619 & & & \\
IAS3R & 0.514 & & & \\
IAS15R & 0.611 & & & \\
IAS9 & & 0.662 & & \\
IAS11 & & 0.625 & & \\
IAS12 & & 0.655 & & \\
IAS13 & & 0.668 & & \\
IAS4 & & & 0.698 & \\
IAS8 & & & 0.660 & \\
IAS14 & & & 0.500 & \\
IAS1 & & & & 0.612 \\
IAS5 & & & & 0.508 \\
IAS7 & & & & 0.550 \\
\hline
\end{tabular}

'None' rotation was used 


\subsection{CCA results}

CCA analysis was performed on SmartPLS software version 3.33 (Ringle et al. 2015) and underneath are shown the two stages for the HOC and LOCs and the steps followed for the reflective-reflective measurement model:

Stage 1 LOC measurement model assessment:

- Step (1) Assessing the indicator loadings and their significance: In Table 4, all the standardized loadings have a value greater than 0.5 and the associated bootstrap T-statistics reveal them significant. According to Hair et al. (2018) stated that in exploratory case, loading can be 0.4 as long as AVE met the minimum threshold value of 0.5 (Hair et al. 2019);

- Step (2) Indicators reliability (items): All the squared individual indicator loadings (reported in Table 4 above) provides a good measure of the amount of variance shared between each single item and the component on which it saturates;

- Step (3) Composite reliability (construct): This index values are more than acceptable, because the CR values for each LOCs are respectively equal to 0.762 , $0.809,0.753,0.773$ and therefore greater than the threshold of 0.700 . In this case, composite reliability (weighted) is more accurate than Cronbach's alpha (unweighted), because indicators are not equally reliable (see Table 5). Moreover, the last two columns show the uni-dimensionality of the sub-scales;

- Step (4) Convergent validity: The average variance extracted (AVE) values, being equal to/exceed the 0.50 threshold for all the LOCs (respectively, AVE $=0.517,0.515,0.512,0.532$ ) are more than acceptable (see Table 5);

- Step (5) Discriminant validity: The Table 6 shows outer loadings (in bold) between the items and correspondent component greater than the cross-loadings with any other component. Forner-Lacker criterion is also satisfied, since

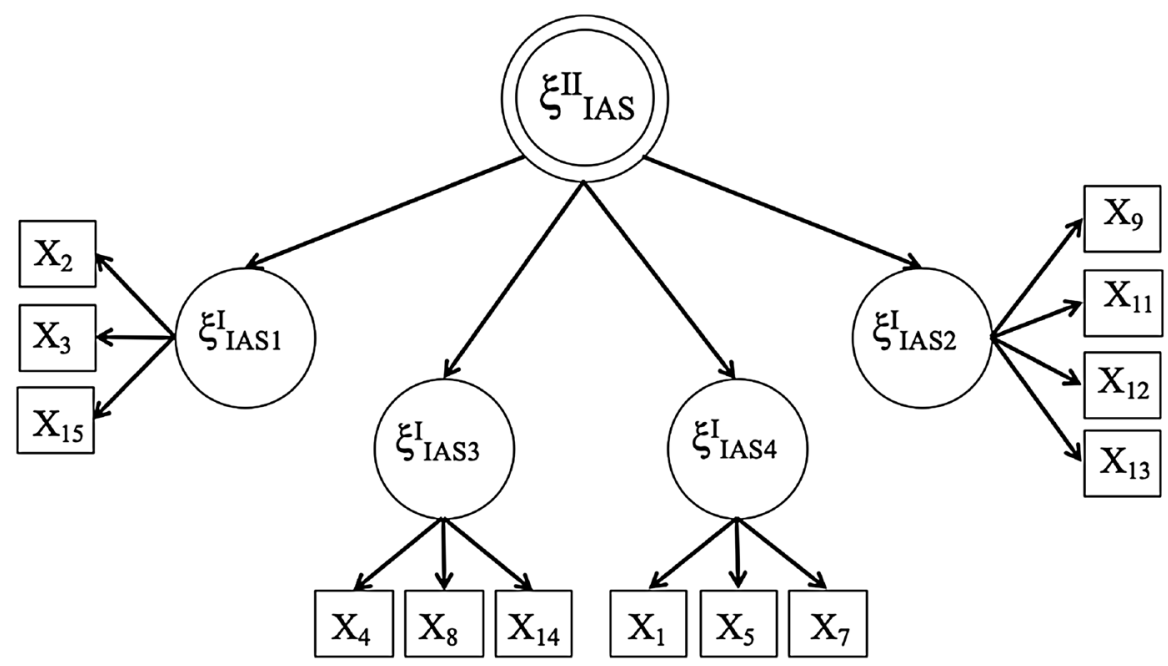

Fig. 2 Theoretical path model 


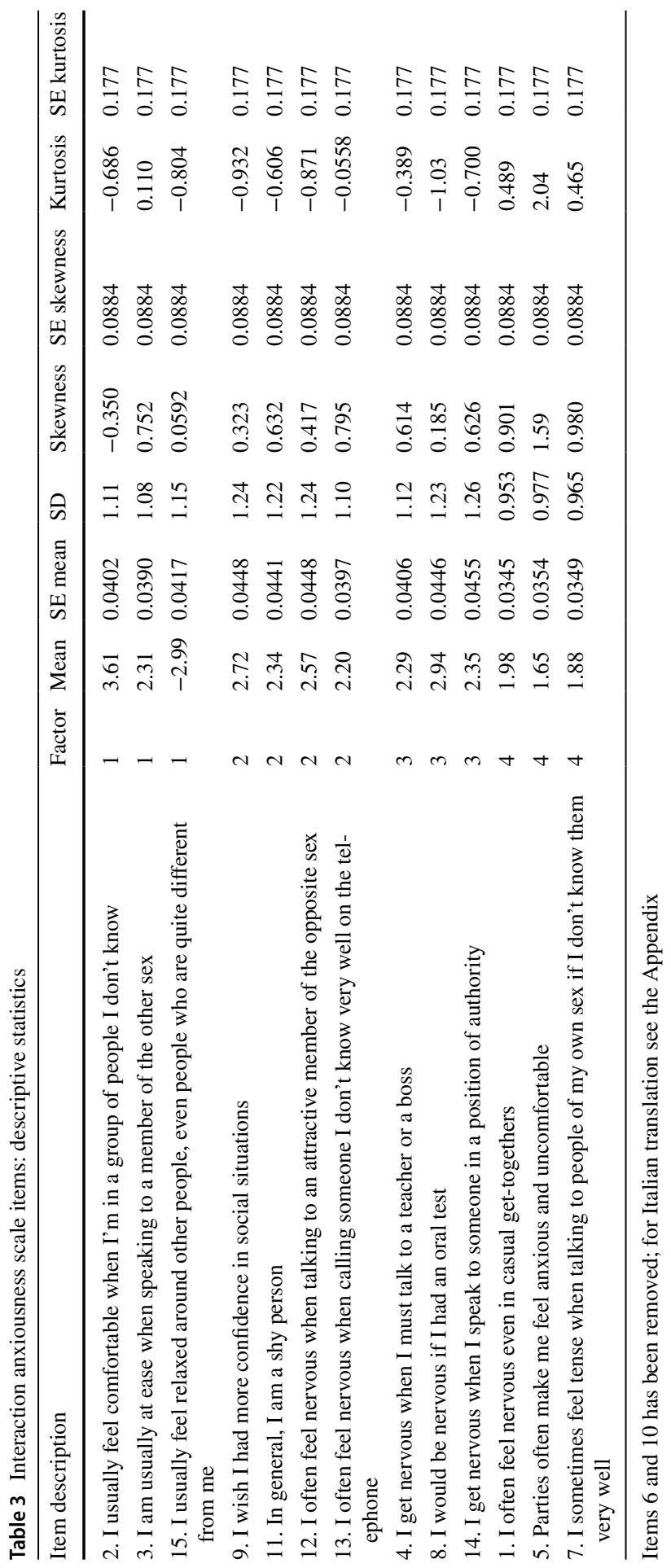


Table 4 Indicators loadings and confidence intervals

\begin{tabular}{lllllll}
\hline Relationship & Original sample & Sample mean & SD & Confidence intervals & T statistics & $p$ values \\
\hline$\xi_{\text {IAS1 }}^{I} \rightarrow$ IAS2R & 0.738 & 0.736 & 0.067 & {$[0.630 ; 0.851]$} & 10.953 & 0.000 \\
$\xi_{\text {IAS1 }}^{I} \rightarrow$ IAS3R & 0.749 & 0.743 & 0.054 & {$[0.666 ; 0.845]$} & 3.757 & 0.000 \\
$\xi_{\text {IAS1 }}^{I} \rightarrow$ IAS15R & 0.667 & 0.658 & 0.085 & {$[0.535 ; 0.815]$} & 7.840 & 0.000 \\
$\xi_{\text {IAS2 }}^{I} \rightarrow$ IAS9 & 0.710 & 0.710 & 0.036 & {$[0.652 ; 0.769]$} & 19.976 & 0.000 \\
$\xi_{\text {IAS2 }}^{I} \rightarrow$ IAS11 & 0.770 & 0.770 & 0.025 & {$[0.730 ; 0.812]$} & 31.031 & 0.000 \\
$\xi_{\text {IAS2 }}^{I} \rightarrow$ IAS12 & 0.703 & 0.702 & 0.031 & {$[0.652 ; 0.755]$} & 22.480 & 0.000 \\
$\xi_{\text {IAS2 }}^{I} \rightarrow$ IAS13 & 0.684 & 0.684 & 0.037 & {$[0.624 ; 0.746]$} & 18.449 & 0.000 \\
$\xi_{\text {IAS3 }}^{I} \rightarrow$ IAS4 & 0.761 & 0.760 & 0.040 & {$[0.697 ; 0.828]$} & 19.114 & 0.000 \\
$\xi_{\text {IAS3 }}^{I} \rightarrow$ IAS8 & 0.819 & 0.817 & 0.030 & {$[0.771 ; 0.870]$} & 27.041 & 0.000 \\
$\xi_{\text {IAS3 }}^{I} \rightarrow$ IAS14 & 0.535 & 0.533 & 0.073 & {$[0.417 ; 0.658]$} & 7.314 & 0.000 \\
$\xi_{\text {IAS4 }}^{I} \rightarrow$ IAS1 & 0.732 & 0.731 & 0.034 & {$[0.676 ; 0.789]$} & 21.403 & 0.000 \\
$\xi_{\text {IAS4 }}^{I} \rightarrow$ IAS5 & 0.708 & 0.706 & 0.042 & {$[0.641 ; 0.780]$} & 16.695 & 0.000 \\
$\xi_{\text {IAS4 }}^{I} \rightarrow$ IAS7 & 0.749 & 0.748 & 0.034 & {$[0.693 ; 0.806]$} & 21.865 & 0.000 \\
\hline
\end{tabular}

the square root of AVE of each component is greater than its correlation with other components (see Table 7). In the end, Table 8 reports the HTMT values and the bootstrap confidence interval in the parentheses. All the values are below the threshold of 0.85 , showing a a good distinctiveness, with the only exception of the components $\xi_{\text {IAS2 }}^{I}$ and $\xi_{\text {IAS4 }}^{I}$. Still this relationship, since in a scale development and exploratory point of view (Henseler et al. 2015), can be analyzed taking into account the bootstrap $\mathrm{HTMT}_{\text {inference }}$ confidence interval, that reveals empirically distinct components, since the value 1 is not included in. The discriminant validity between the four composites and their higherorder component $\xi_{I A S}^{I I}$ it is not relevant. An incorrect value of discriminant validity between these constructs is expected, because the measurement model of the higher-order component repeats the indicators of its four lower-order components.

Table 5 Reliability and convergent validity

\begin{tabular}{llllll}
\hline & MVs & CR $\left(\rho_{\mathrm{c}}\right)$ & AVE & Eig. 1 & Eig.2 \\
\hline$\xi_{\text {IAS1 }}^{I}$ & 3 & 0.762 & 0.517 & 3.561 & 1.443 \\
$\xi_{\text {IAS2 }}^{I}$ & 4 & 0.809 & 0.515 & 3.414 & 1.066 \\
$\xi_{\text {IAS3 }}^{I}$ & 3 & 0.753 & 0.512 & 2.106 & 0.934 \\
$\xi_{\text {IAS4 }}^{I}$ & 3 & 0.773 & 0.532 & 1.424 & 0.804 \\
\hline
\end{tabular}


Table 6 Crossloading

\begin{tabular}{lllll}
\hline & $\xi_{\text {IAS1 }}^{I}$ & $\xi_{\text {IAS2 }}^{I}$ & $\xi_{\text {IAS3 }}^{I}$ & $\xi_{\text {IAS4 }}^{I}$ \\
\hline IAS2R & $\mathbf{0 . 7 3 8}$ & 0.212 & 0.144 & 0.099 \\
IAS3R & $\mathbf{0 . 7 4 9}$ & 0.207 & -0.004 & 0.138 \\
IAS15R & $\mathbf{0 . 6 6 7}$ & 0.183 & -0.058 & 0.148 \\
IAS9 & 0.192 & $\mathbf{0 . 7 1 0}$ & 0.282 & 0.459 \\
IAS11 & 0.332 & $\mathbf{0 . 7 7 0}$ & 0.324 & 0.452 \\
IAS12 & 0.169 & $\mathbf{0 . 7 0 3}$ & 0.364 & 0.401 \\
IAS13 & 0.091 & $\mathbf{0 . 6 8 4}$ & 0.360 & 0.390 \\
IAS8 & 0.054 & 0.376 & $\mathbf{0 . 8 1 9}$ & 0.198 \\
IAS4 & 0.036 & 0.337 & $\mathbf{0 . 7 6 1}$ & 0.169 \\
IAS14 & 0.006 & 0.270 & $\mathbf{0 . 5 3 5}$ & 0.093 \\
IAS1 & 0.146 & 0.413 & 0.166 & $\mathbf{0 . 7 3 2}$ \\
IAS5 & 0.122 & 0.412 & 0.057 & $\mathbf{0 . 7 0 8}$ \\
IAS7 & 0.118 & 0.471 & 0.248 & $\mathbf{0 . 7 4 9}$ \\
\hline
\end{tabular}

Table 7 Fornell-Larcker criterion

\begin{tabular}{lllll}
\hline & $\xi_{\text {IAS1 }}^{I}$ & $\xi_{\text {IAS2 }}^{I}$ & $\xi_{\text {IAS3 }}^{I}$ & $\xi_{\text {IAS4 }}^{I}$ \\
\hline$\xi_{\text {IAS1 }}^{I}$ & 0.719 & & & \\
$\xi_{\text {IAS2 }}^{I}$ & 0.280 & 0.718 & & \\
$\xi_{\text {IAS3 }}^{I}$ & 0.048 & 0.462 & 0.716 & \\
$\xi_{\text {IAS4 }}^{I}$ & 0.176 & 0.594 & 0.222 & 0.730 \\
\hline
\end{tabular}

Table 8 HTMT matrix and confidence intervals

\begin{tabular}{lllc}
\hline & $\xi_{\text {IAS } 1}^{I}$ & $\xi_{\text {IAS2 }}^{I}$ & $\xi_{\text {IAS3 }}^{I}$ \\
\hline$\xi_{\text {IAS2 }}^{I}$ & $0.459[0.330 ; 0.588]$ & & \\
$\xi_{\text {IAS3 }}^{I}$ & $0.259[0.157 ; 0.361]$ & $0.784[0.660 ; 0.908]$ & \\
$\xi_{\text {IAS4 }}^{I}$ & $0.332[0.186 ; 0.479]$ & $0.921[0.865 ; 0.976]$ & 0.394 \\
& & & {$[0.263 ;$} \\
& & & $0.526]$ \\
\hline
\end{tabular}

Stage 2: HOC measurement model assessment:

- Step (1): Reliability: The composite reliability being equal to 0.781 , provides clear support for the higher-order construct's internal consistency reliability, because it exceeds the threshold of 0.7 ;

- Step (2): Convergent validity: AVE index is $\left(0.412^{2}+0.919^{2}+\right.$ $\left.0.606^{2}+0.762^{2}\right) / 4=0.491$, with a bootstrap confidence interval [0.419; 0.572] Convergent validity is still acceptable since confidence interval includes 0.5 and also, as suggested by Fornell and Larcker (1981), even low of 0.5, the composite reliability is higher than 0.6 ; 
- Step (3): Discriminant validity. For the proposed model, discriminant validity can not be evaluated, since the HOC is not a nomological network;

- Step (4): Assessing the LOCs loadings and their significance: Then, it is important to analyze the structural model using bootstrapping method with 300 subsamples and found that all structural model relationships are significant $(p<0.05)$ (see Table 9). The explained variance of the HOC is mainly due to $\xi_{\text {IAS2 }}^{I}(0.919)$ followed by $\xi_{\text {IAS4 }}^{I}(0.762), \xi_{\text {IAS3 }}^{I}(0.606)$ and in the end by $\xi_{\text {IAS1 }}^{I}$ (0.412). After these assessment stages, it is possible to confirm that the IAS scale, through CCA, reveals a structure with four composites/factors. Based on this notion, IAS can be conceptualized as a higher-order construct comprising the four lower-order components $\xi_{\mathrm{IAS} 1}^{I}, \xi_{\mathrm{IAS} 2}^{I}, \xi_{\mathrm{IAS} 3}^{I}$ and $\xi_{\mathrm{IAS} 4}^{I}$, as reported in the Fig. 3. In particular, $\xi_{\mathrm{IAS} 1}^{I}$ is made up of items (measurable variables) 2, 3 and 15; $\xi_{\mathrm{IAS} 2}^{I}$ from items $9,11,12$ and $13, \xi_{\mathrm{IAS} 3}^{I}$ from items 4,8 and 14 , while $\xi_{\mathrm{IAS} 4}^{I}$ from items 1,5 and 7.

\section{Discussion}

The results indicate a four-factors structure of the IAS for Italian adolescents. Through the use of CCA, we find support to the appropriateness of a reflectivereflective IAS measurement model; more precisely, IAS is best conceptualized as a second-order reflective-reflective measurement model. To our knowledge, this is the first study to evaluate the appropriateness of the IAS and to assess its factor structure using a higher-order modelling method.

Based on conceptual, pragmatic, and statistical evidence, our innovative secondorder reflective-reflective IAS measurement model asserts that the presence of a certain level of anxiety in the adolescent's social interactions gives rise to discomfort and sense of inadequacy in interactions, nervousness when interacting with authority figures, discomfort in unstructured interactions or to comfortability in interactions with unknown other-when the levels of social anxiety are lower.

More specifically, respect to the first factor $\left(\xi_{\mathrm{IAS} 1}^{I}\right)$ "comfortability in interactions with Unknown Other", the anxious adolescent reports low positive subjective experiences - such as feeling comfortable and relaxed-in a group of people he/she does not know, a conversation with someone of the opposite sex, and among people different from him/her. A similar finding can be traced in a study by Myers et al. (2002) which identified novel social situation fears (e.g. being surrounded by unknown

Table 9 Higher-order measurement model (structural model estimates)

\begin{tabular}{lllllll}
\hline Relationship & Original sample & Sample mean & SD & Confidence intervals & T statistics & $p$ values \\
\hline$\xi_{\text {IAS }}^{I I} \rightarrow \xi_{\text {IAS1 }}^{I}$ & 0.412 & 0.418 & 0.077 & {$[0.280 ; 0.532]$} & 5.377 & 0.000 \\
$\xi_{\text {IAS }}^{I I} \rightarrow \xi_{\text {IAS2 }}^{I}$ & 0.919 & 0.919 & 0.010 & {$[0.904 ; 0.936]$} & 92.187 & 0.000 \\
$\xi_{\text {IAS }}^{I I} \rightarrow \xi_{\text {IAS3 }}^{I}$ & 0.606 & 0.609 & 0.054 & {$[0.514 ; 0.693]$} & 11.174 & 0.000 \\
$\xi_{\text {IAS }}^{I I} \rightarrow \xi_{\text {IAS4 }}^{I}$ & 0.762 & 0.762 & 0.026 & {$[0.718 ; 0.804]$} & 29.106 & 0.000 \\
\hline
\end{tabular}




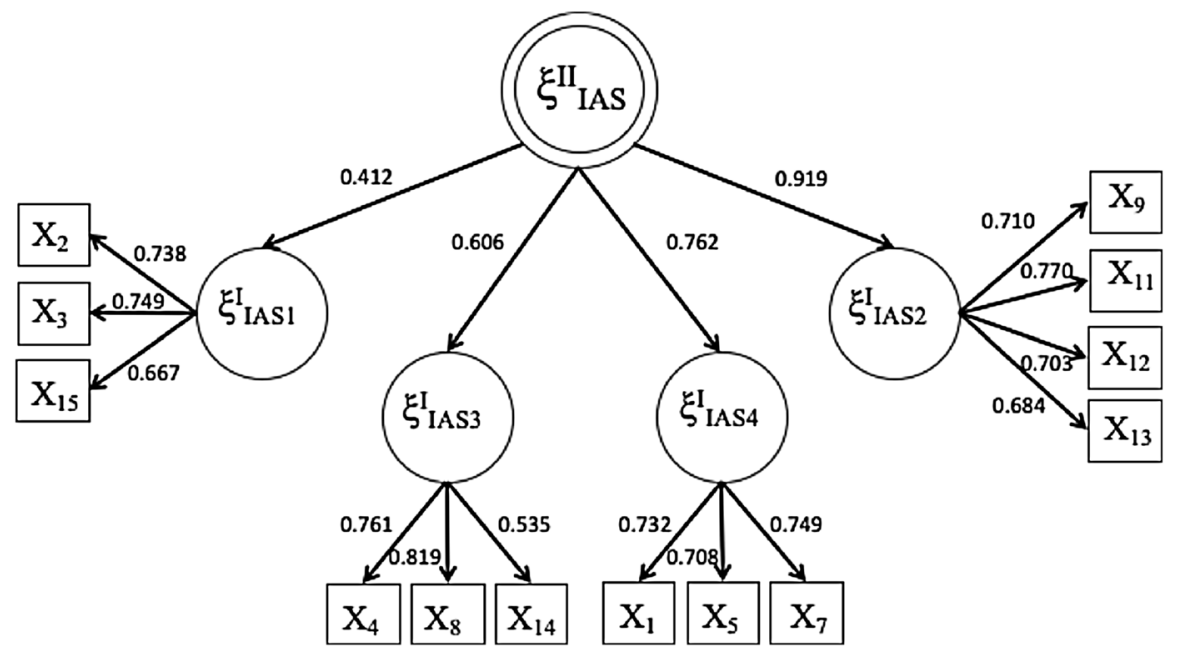

Fig. 3 Path model with the estimated parameters

people) as a sub-dimension of adolescents social anxiety. The second factor $\left(\xi_{\text {IAS2 }}^{I}\right)$ "discomfort and sense of inadequacy in interactions" consists of items describing lack of self-confidence, shyness, and nervousness in various interactive scenarios: in this case, the presence of social anxiety rises feelings of inadequacy, namely feeling and seeing oneself as incompetent to cope with social situations, inferior and unattractive-well-recognized signs of social anxiety also by other scholars (e.g. Iwase et al. (2000); Matos et al. (2013)). The factor $\left(\xi_{\text {IAS3 }}^{I}\right)$ "nervousness when interacting with authority" identifies difficulties in conversations with teachers, boss, and authority figures as well as in oral text: the fear of authority is indeed often reported by adolescents high in social anxiety (Garcia-Lopez et al. 2008; Ranta et al. 2007). Finally, the fourth factor ( $\left.\xi_{\mathrm{IAS} 4}^{I}\right)$ "discomfort in unstructured interactions" refers to negative subjective experiences in situations such as parties, causal encounters, and interactions with unknown peers of one's own sex: although such interactions can be considered common in adolescence due to a major social exploration, they may rise nervousness in social anxious adolescents since their unstructured nature, that is a higher unpredictability (Clauss et al. 2019; Smith et al. 2020).

Conceptually, it seems useful to have an instrument which offers different social scenarios, recalling the subjective experience associated with them. These subjective experiences can be in turn connected to the subject's self-image-very salient during adolescence (Erikson 1968; Di Blasi et al. 2015)—namely if he/she perceives him/ herself alternatively as an uneasy or a confident social actor. Therefore, as pointed out by the existence of the 1 st factor $\left(\xi_{\text {IAS1 }}^{I}\right)$, an adolescent who feel comfortable in social situations-i.e. who perceives him/herself as a proper social actor-does not seem scared to interact with someone who can be defined Unknown, namely of the opposite sex, different from her/his, or unknown. On the contrary, social anxious adolescents are too much worried about the first impression given to people they do not know (Cannon et al. 2020; Glenn et al. 2019) as well as in heterosocial 
encounters (Asher and Aderka 2020; La Greca and Harrison 2005). Consistently, as highlighted by the 2 nd factor $\left(\xi_{\mathrm{IAS} 2}^{I}\right)$, they report discomfort in social situations in general as well as in interactions with someone unknown who cannot be seen (i.e. in interactions through the phone) or who belongs to the opposite sex (i.e. someone attractive): all this scenarios suggest that social anxiety enhance their sense of inadequacy which is associated with shyness, lacking of confidence (Weeks et al. 2016) as well as difficulties when interacting with someone appealing (Leary and Jongman-Sereno 2014) or a stranger by voice (Reid and Reid 2007). In the case of the 4 th factor ( $\left.\xi_{\mathrm{IAS} 4}^{I}\right)$, the adolescent-social actor high in social anxiety feels discomfort in unstructured interactions, namely situations to handle with unclear expectations such as parties and new encounters (Glenn et al. 2019; Hofmann et al. 1999). Respect to the interactions with authorities collected in the third dimension ( $\left.\xi_{\mathrm{IAS} 4}^{I}\right)$, it is possible to interpret such finding considering that figures in a position of authority are particularly problematic for social anxious people (Leary and Kowalski 1986; Mehtalia and Vankar 2004) especially adolescents may have many concerns regarding the way in which they were evaluated by their teachers and similar, because during this stage of age they are facing for other authority figures beyond their parents.

Another aspect that has to be considered is that although the original version of the instrument developed by Leary (1983) among American university students has a one-factor structure, our results indicate the existence of four factors. A study in the European context (i.e. Spain) among people aged from 20 to 41 years old has found either a one-factor and a two-factors structure, the latter with a small second factor related to interactions with authorities (e. g., professor, boss), suggesting that social anxious individual are particularly sensitive to evaluations from people in an authority position, as also emerged from our sample. Differences in the factorial structure could depend firstly on the innovative statistical method of investigating the factorial structure, as mentioned above; furthermore, it could mean that the phenomenon studied in the target culture has peculiar characteristics, so that the different factorial structures can reveal cultural differences across different contexts, for instance with European people (i.e. Italians and Spanish) more sensitive to authorities. Another possible explanation can be offered referring to the specific developmental stage of our sample: the four-factors emerged in our study suggest that social anxiousness in Italian adolescents is reflected on interactions with an unknown other, interactions with authorities, unstructured encounters, and in their sense of inadequacy-scenarios which can be connected to the specific social experiences made in adolescence due to a major openness to the social world (Mohammadi et al. 2020; Wittchen et al. 1999).

\subsection{Limitations and further direction of research}

Our sample was limited to a specific Italian area, thus it is not representative of diverse locations and limits the generalizability of results across subpopulations. Studies with a more heterogeneous samples are necessary, as well as studies with adolescent clinical samples, in order to replicate the second-order four-components 
model or to make comparison studies and determine the most appropriate measurement model.

A new survey could help also to evaluate to remove $\xi_{\text {IAS1 }}^{I}$, or to improve the items of this LOC, since the coefficient is the lowest. Moreover, an extra analysis for the relationship between $\xi_{\text {IAS2 }}^{I}$ and $\xi_{\text {IAS4 }}^{I}$ could be conducted, since, even if they are is still distinct components, the value in HTMT matrix could be improved, in way to reduce the confidence interval and also the criterion value.

An addition limitation of our study was that we did not include multiple assessment points using the IAS, hindering the measurement invariance of the scale across time. Despite these limitations, this study was the first to evaluate the factor structure and model specifications of the IAS among Italian adolescents using CCA and to offer favorable findings of the higher-order reflective-reflective IAS model.

Funding Open access funding provided by Università del Salento within the CRUI-CARE Agreement.

\section{Declarations}

Conflict of interest No potential conflict of interest was reported by the author(s).

Open Access This article is licensed under a Creative Commons Attribution 4.0 International License, which permits use, sharing, adaptation, distribution and reproduction in any medium or format, as long as you give appropriate credit to the original author(s) and the source, provide a link to the Creative Commons licence, and indicate if changes were made. The images or other third party material in this article are included in the article's Creative Commons licence, unless indicated otherwise in a credit line to the material. If material is not included in the article's Creative Commons licence and your intended use is not permitted by statutory regulation or exceeds the permitted use, you will need to obtain permission directly from the copyright holder. To view a copy of this licence, visit http://creativecommons.org/licen ses/by/4.0/.

\section{References}

Asher M, Aderka IM (2020) Dating with social anxiety: an empirical examination of momentary anxiety and desire for future interaction. Clin Psychol Sci 8(1):99-110

Barroso C, Picón A (2012) Multi-dimensional analysis of perceived switching costs. Ind Mark Manag 41(3):531-543

Beck AT, Steer RA, Brown GK et al (1996) Manual for the beck depression inventory-II. Psychological Corporation, San Antonio

Becker JM, Klein K, Wetzels M (2012) Hierarchical latent variable models in pls-sem: guidelines for using reflective-formative type models. Long Range Plan 45(5-6):359-394

Beesdo K, Bittner A, Pine DS, Stein MB, Höfler M, Lieb R, Wittchen HU (2007) Incidence of social anxiety disorder and the consistent risk for secondary depression in the first three decades of life. Arch Gen Psychiatry 64(8):903-912

Bradley W, Henseler J (2007) Modeling reflective higher-order constructs using three approaches with pls path modeling: a monte carlo comparison. In: Thyne M, Deans KR, Gnoth J (ed) Australian and New Zealand Marketing Academy Conference Proceedings, pp. 791-800

Buckner JD, Bonn-Miller MO, Zvolensky MJ, Schmidt NB (2007) Marijuana use motives and social anxiety among marijuana-using young adults. Addict Behav 32(10):2238-2252 
Buckner JD, Schmidt NB, Lang AR, Small JW, Schlauch RC, Lewinsohn PM (2008) Specificity of social anxiety disorder as a risk factor for alcohol and cannabis dependence. J Psychiatr Res 42(3):230-239

Buhrmester D, Furman W (1987) The development of companionship and intimacy. Child development, Vol. 58, No. 4, pp 1101-1113

Caballo VE, Arias B, Salazar IC, Calderero M, Irurtia MJ, Ollendick TH (2012) A new self-report assessment measure of social phobia/anxiety in children: the social anxiety questionnaire for children (saq-c24). Behav Psychol Conduct 20(3):485-503

Cannon CJ, Makol BA, Keeley LM, Qasmieh N, Okuno H, Racz SJ, De Los Reyes A (2020) A paradigm for understanding adolescent social anxiety with unfamiliar peers: conceptual foundations and directions for future research. Clin Child Fam Psychol Rev 23(3):338-364

Caplan SE (2006) Relations among loneliness, social anxiety, and problematic internet use. CyberPsychol Behav 10(2):234-242

Carpita M, Ciavolino E (2017) A generalized maximum entropy estimator to simple linear measurement error model with a composite indicator. Adv Data Anal Classif 11(1):139-158

Cheah JH, Ting H, Ramayah T, Memon MA, Cham TH, Ciavolino E (2019) A comparison of five reflective-formative estimation approaches: reconsideration and recommendations for tourism research. Qual Quant 53(3):1421-1458

Cheek JM, Buss AH (1981) Shyness and sociability. J Pers Soc Psychol 41(2):330

Ciavolino E, Al-Nasser AD (2009) Comparing generalised maximum entropy and partial least squares methods for structural equation models. J Nonparametr Stat 21(8):1017-1036

Ciavolino E, Dahlgaard JJ (2009) Simultaneous equation model based on the generalized maximum entropy for studying the effect of management factors on enterprise performance. J Appl Stat 36(7):801-815

Ciavolino E, Nitti M (2013b) Using the hybrid two-step estimation approach for the identification of second-order latent variable models. J Appl Stat 40(3):508-526

Ciavolino E, Nitti M (2013a) Simulation study for pls path modelling with high-order construct: a job satisfaction model evidence. In: Advanced dynamic modeling of economic and social systems. Springer, pp 185-207

Clark LA, Watson D (2016) Constructing validity: basic issues in objective scale development. In: Kazdin AE (ed) Methodological issues and strategies in clinical research. American Psychological Association, pp. 187-203

Clauss JA, Avery SN, Benningfield MM, Blackford JU (2019) Social anxiety is associated with bnst response to unpredictability. Depress Anxiety 36(8):666-675

Contardi A, Farina B, Fabbricatore M, Tamburello S, Scapellato P, Penzo I, Tamburello A, Innamorati M (2013) Difficulties in emotion regulation and personal distress in young adults with social anxiety. Riv Psichiatr 48(2): 155-161

Costello EJ, Mustillo S, Erkanli A, Keeler G, Angold A (2003) Prevalence and development of psychiatric disorders in childhood and adolescence. Arch Gen Psychiatry 60(8):837-844

Cronbach LJ, Gleser GC (1957) Psychological tests and personnel decisions

Crowne DP, Marlowe D (1964) The approval motive: studies in evaluative dependence. Wiley, New York

Dakanalis A, Carrà G, Calogero R, Zanetti MA, Volpato C, Riva G, Clerici M, Cipresso P (2016) The social appearance anxiety scale in Italian adolescent populations: construct validation and group discrimination in community and clinical eating disorders samples. Child Psychiatry Hum Dev 47(1):133-150

Davidson CL, Wingate LR, Grant DM, Judah MR, Mills AC (2011) Interpersonal suicide risk and ideation: the influence of depression and social anxiety. J Soc Clin Psychol 30(8):842-855

De Berardis D, Carano A, Gambi F, Campanella D, Giannetti P, Ceci A, Mancini E, La Rovere R, Cicconetti A, Penna L et al (2007) Alexithymia and its relationships with body checking and body image in a non-clinical female sample. Eat Behav 8(3):296-304

Di Blasi M, Cavani P, Pavia L, Lo Baido R, La Grutta S, Schimmenti A (2015) The relationship between self-image and social anxiety in adolescence. Child Adolesc Mental Health 20(2):74-80

Erikson EH (1968) Identity: youth and crisis, vol 7. WW Norton \& Company, New York

Fenigstein A, Scheier MF, Buss AH (1975) Public and private self-consciousness: assessment and theory. J Consult Clin Psychol 43(4):522

Fornell C, Larcker DF (1981) Evaluating structural equation models with unobservable variables and measurement error. J Mark Res 18(1):39-50 
Gallagher M, Prinstein MJ, Simon V, Spirito A (2014) Social anxiety symptoms and suicidal ideation in a clinical sample of early adolescents: examining loneliness and social support as longitudinal mediators. J Abnorm Child Psychol 42(6):871-883

Garcia-Lopez LJ, Hidalgo MD, Beidel DC, Olivares J, Turner S (2008) Brief form of the social phobia and anxiety inventory (spai-b) for adolescents. Eur J Psychol Assess 24(3):150-156

Glass CR, Merluzzi TV, Biever JL, Larsen KH (1982) Cognitive assessment of social anxiety: development and validation of a self-statement questionnaire. Cogn Ther Res 6(1):37-55

Glenn LE, Keeley LM, Szollos S, Okuno H, Wang X, Rausch E, Deros DE, Karp JN, Qasmieh N, Makol BA et al (2019) Trained observers' ratings of adolescents' social anxiety and social skills within controlled, cross-contextual social interactions with unfamiliar peer confederates. J Psychopathol Behav Assess 41(1):1-15

Gold AH, Malhotra A, Segars AH (2001) Knowledge management: an organizational capabilities perspective. J Manag Inf Syst 18(1):185-214

Hair JF, Sarstedt M, Ringle CM, Mena JA (2012) An assessment of the use of partial least squares structural equation modeling in marketing research. J Acad Mark Sci 40(3):414-433

Hair JF Jr, Hult GTM, Ringle C, Sarstedt M (2016) A primer on partial least squares structural equation modeling (PLS-SEM). Sage Publications, Thousand Oaks

Hair JF, Hult GTM, Ringle CM, Sarstedt M, Thiele KO (2017) Mirror, mirror on the wall: a comparative evaluation of composite-based structural equation modeling methods. J Acad Mark Sci 45(5):616-632

Hair JF Jr, Sarstedt M, Ringle CM, Gudergan SP (2018) Advanced issues in partial least squares structural equation modeling. Sage Publications, Thousand Oaks

Hair JF Jr, Page M, Brunsveld N (2019) Essentials of business research methods. Routledge, Milton Park

Hair JF Jr, Howard MC, Nitzl C (2020) Assessing measurement model quality in pls-sem using confirmatory composite analysis. J Bus Res 109:101-110

Hair J, Black W, Babin B, Anderson R (2019) Multivariate data analysis, 8th edn. Cengage learning emea, Andover. Hampshire

Harter S, Stocker C, Robinson NS (1996) The perceived directionality of the link between approval and self-worth: The liabilities of a looking gladd self-orientation among young adolescents. J Res Adolesc

Henseler J, Dijkstra TK, Sarstedt M, Ringle CM, Diamantopoulos A, Straub DW, Ketchen DJ Jr, Hair JF, Hult GTM, Calantone RJ (2014) Common beliefs and reality about pls: comments on Rönkkö and Evermann (2013). Organ Res Methods 17(2):182-209

Henseler J, Ringle CM, Sarstedt M (2015) A new criterion for assessing discriminant validity in variance-based structural equation modeling. J Acad Mark Sci 43(1):115-135

Henseler J, Hubona G, Ray PA (2016) Using pls path modeling in new technology research: updated guidelines. Ind Manag Data Syst

Hofmann SG, Albano AM, Heimberg RG, Tracey S, Chorpita BF, Barlow DH (1999) Subtypes of social phobia in adolescents. Depress Anxiety 9(1):15-18

Hulland J (1999) Use of partial least squares (pls) in strategic management research: a review of four recent studies. Strateg Manag J 20(2):195-204

Hwang H, Takane Y (2004) Generalized structured component analysis. Psychometrika 69(1):81-99

Iwase M, Nakao K, Takaishi J, Yorifuji K, Ikezawa K, Takeda M (2000) An empirical classification of social anxiety: performance, interpersonal and offensive. Psychiatry Clin Neurosci 54(1):67-75

Johnson RE, Rosen CC, Chang CH (2011) To aggregate or not to aggregate: steps for developing and validating higher-order multidimensional constructs. J Bus Psychol 26(3):241-248

Jolliffe IT, Cadima J (2016) Principal component analysis: a review and recent developments. Philos Trans R Soc A Math Phys Eng Sci 374(2065):20150202

Jöreskog KG (1970) A general method for estimating a linear structural equation system. ETS Research Bulletin Series 1970(2):i-41

Kline RB (2011) Principles and practice of structural equation modeling (3. bask1). Guilford, New York

La Greca AM, Harrison HM (2005) Adolescent peer relations, friendships, and romantic relationships: do they predict social anxiety and depression? J Clin Child Adolesc Psychol 34(1):49-61

Larson RW, Richards MH (1994) Family emotions: do young adolescents and their parents experience the same states? J Res Adolesc 4(4):567-583

Leary MR, Jongman-Sereno KP (2014) Social anxiety as an early warning system: a refinement and extension of the self-presentation theory of social anxiety. In: Social anxiety. Elsevier, pp 579-597 
Leary MR (2013) Social anxiety, shyness, and measures of personality and social psychological attitudes, vol 1, pp 161-176

Leary MR, Schlenker BR (1981) The social psychology of shyness: a self-presentation model. In: Impression management: theory and social psychological research, pp 335-358

Leary MR (1983) A brief version of the fear of negative evaluation scale. Pers Soc Psychol Bull 9(3):371-375

Leary MR, Kowalski RM (1986) Manual for the interaction anxiousness scale. Select Press, San Rafael

Leary MR, Kowalski RM (1993) The interaction anxiousness scale: construct and criterion-related validity. J Pers Assess 61(1):136-146

Lee BW, Stapinski LA (2012) Seeking safety on the internet: relationship between social anxiety and problematic internet use. J Anxiety Disord 26(1):197-205

Leigh E, Clark DM (2018) Understanding social anxiety disorder in adolescents and improving treatment outcomes: applying the cognitive model of Clark and Wells (1995). Clin Child Fam Psychol Rev 21(3):388-414

Liebowitz MR (1987) Social phobia. Pharmacopsychiatry Mod Probl

Lohmöller JB (1989) Predictive vs. structural modeling: Pls vs. ml. In: Latent variable path modeling with partial least squares. Springer, pp 199-226

Matos M, Pinto-Gouveia J, Gilbert P (2013) The effect of shame and shame memories on paranoid ideation and social anxiety. Clin Psychol Psychother 20(4):334-349

Mazzone L, Ducci F, Scoto MC, Passaniti E, D’Arrigo VG, Vitiello B (2007) The role of anxiety symptoms in school performance in a community sample of children and adolescents. BMC Public Health 7(1):1-6

McElhaney KB, Antonishak J, Allen JP (2008) they like me, they like me not: popularity and adolescents' perceptions of acceptance predicting social functioning over time. Child Dev 79(3):720-731

Mehtalia K, Vankar G (2004) Social anxiety in adolescents. Indian J Psychiatry 46(3):221

Michiel Westenberg P, Drewes MJ, Goedhart AW, Siebelink BM, Treffers PD (2004) A developmental analysis of self-reported fears in late childhood through mid-adolescence: social-evaluative fears on the rise? J Child Psychol Psychiatry 45(3):481-495

Mohammadi MR, Salehi M, Khaleghi A, Hooshyari Z, Mostafavi SA, Ahmadi N, Hojjat SK, Safavi P, Amanat M (2020) Social anxiety disorder among children and adolescents: a nationwide survey of prevalence, socio-demographic characteristics, risk factors and co-morbidities. J Affect Disord 263:450-457

Mvududu NH, Sink CA (2013) Factor analysis in counseling research and practice. Couns Outcome Res Eval 4(2):75-98

Myers MG, Stein MB, Aarons GA (2002) Cross validation of the social anxiety scale for adolescents in a high school sample. J Anxiety Disord 16(2):221-232

Netemeyer RG, Bearden WO, Sharma S (2003) Scaling procedures: issues and applications. Sage Publications, Thousand Oaks

Nitti M, Ciavolino E (2014) A deflated indicators approach for estimating second-order reflective models through pls-pm: an empirical illustration. J Appl Stat 41(10):2222-2239

Nunnally JC (1978) Psychometric theory, 2nd edn. Mcgraw Hill Book Company, New York

Offer D, Ostrov E, Howard K, Dolan S (1989) The offer self-image questionnaire for adolescents (osiq). Center for the Study of Adolescence, Singer Pavilion, Michael Reese Hospital and Medical Center, Chicago

Ogliari A, Scaini S, Kofler MJ, Lampis V, Zanoni A, Pesenti-Gritti P, Spatola CA, Battaglia M, Beidel DC (2011) Psychometric properties of the social phobia and anxiety inventory for children (spai-c). Eur J Psychol Assess

Polites GL, Roberts N, Thatcher J (2012) Conceptualizing models using multidimensional constructs: a review and guidelines for their use. Eur J Inf Syst 21(1):22-48

Ranta K, Kaltiala-Heino R, Koivisto AM, Tuomisto MT, Pelkonen M, Marttunen M (2007) Age and gender differences in social anxiety symptoms during adolescence: the social phobia inventory (spin) as a measure. Psychiatry Res 153(3):261-270

Reid DJ, Reid FJ (2007) Text or talk? Social anxiety, loneliness, and divergent preferences for cell phone use. CyberPsychol Behav 10(3):424-435

Rigdon EE (2014) Rethinking partial least squares path modeling: breaking chains and forging ahead. Long Range Plan 47(3):161-167

Rigdon EE (2016) Choosing pls path modeling as analytical method in European management research: a realist perspective. Eur Manag J 34(6):598-605 
Rigdon EE, Sarstedt M, Ringle CM (2017) On comparing results from cb-sem and pls-sem: five perspectives and five recommendations. Mark ZFP J Res Manag 39(3):4-16

Ringle CM, Sarstedt M, Straub DW (2012) Editor's comments: a critical look at the use of pls-sem in "mis quarterly". MIS Q iii-xiv

Ringle CM, Wende S, Becker JM (2015) SmartPLS 3. Bönningstedt: SmartPLS. Retrieved from https:// www.smartpls.com

Sanz J (1994) The Spanish version of the interaction anxiousness scale: psychometric properties and relationship with depression and cognitive factors. Eur J Psychol Assess 10(2):129-135

Sarstedt M, Hair JF Jr, Cheah JH, Becker JM, Ringle CM (2019) How to specify, estimate, and validate higher-order constructs in pls-sem. Australas Mark J (AMJ) 27(3):197-211

Schuberth F, Henseler J, Dijkstra TK (2018) Confirmatory composite analysis. Front Psychol 9:2541

Shaffer JP (1995) Multiple hypothesis testing. Annu Rev Psychol 46(1):561-584

Sharma P, Sarstedt M, Shmueli G, Kim KH, Thiele KO (2019) Pls-based model selection: the role of alternative explanations in information systems research. J Assoc Inf Syst 20(4):4

Smith A, Nelson E, Kircanski K, Rappaport B, Do Q, Leibenluft E, Pine D, Jarcho J (2020) Social anxiety and age are associated with neural response to social evaluation during adolescence. Dev Cogn Neurosci 42:100768

Spensieri V, Cerutti R, Presaghi F, Amendola S, Crozier WR (2019) Italian validation of the children's shyness questionnaire: exploring associations between shyness and psychosocial functioning. PLoS One 14(6):e0217722

Stein MB, Fuetsch M, Müller N, Höfler M, Lieb R, Wittchen HU (2001) Social anxiety disorder and the risk of depression: a prospective community study of adolescents and young adults. Arch Gen Psychiatry 58(3):251-256

Subasi G (2007) Some variables for social anxiety prediction in college students. Egitim ve Bilim 32(144):3

Subasi HG (2013) The validity and reliability of the interaction anxiousness scale: gender and social status differences among Turkish adolescents. Int J Humanit Soc Sci 3(3):262-269

Teo TS, Srivastava SC, Jiang L (2008) Trust and electronic government success: an empirical study. J Manag Inf Syst 25(3):99-132

Van Ameringen M, Mancini C, Farvolden P (2003) The impact of anxiety disorders on educational achievement. J Anxiety Disord 17(5):561-571

Van Riel AC, Henseler J, Kemény I, Sasovova Z (2017) Estimating hierarchical constructs using consistent partial least squares. Ind Manag Data Syst

Venuleo C, Ferrante L, Rollo S (2020) Facing life problems through the internet. The link between psychosocial malaise and problematic internet use in an adolescent sample. J Gambl Issues 46(2):107-131

Vinzi VE, Chin WW, Henseler J, Wang H et al (2010) Handbook of partial least squares, vol 201. Springer, Berlin

Watson D, Friend R (1969) Measurement of social-evaluative anxiety. J Consult Clin Psychol 33(4):448

Weeks M, Ooi LL, Coplan RJ (2016) Cognitive biases and the link between shyness and social anxiety in early adolescence. J Early Adolesc 36(8):1095-1117

Wetzels M, Odekerken-Schröder G, Van Oppen C (2009) Using pls path modeling for assessing hierarchical construct models: guidelines and empirical illustration. MIS Q 177-195

Wittchen HU, Stein MB, Kessler RC (1999) Social fears and social phobia in a community sample of adolescents and young adults: prevalence, risk factors and co-morbidity. Psychol Med 29(2):309-323

Wold H (1975) Path models with latent variables: the nipals approach. In: Quantitative sociology. Elsevier, pp 307-357

Wold H (1982) Soft modeling: the basic design and some extensions. In: Systems under indirect observation: causality, structure, prediction, Part II, vol 2. North Holland, Amsterdam, pp 1-54

Publisher's Note Springer Nature remains neutral with regard to jurisdictional claims in published maps and institutional affiliations. 


\title{
Authors and Affiliations
}

\section{Enrico Ciavolino ${ }^{1,3}$ (1) - Lucrezia Ferrante ${ }^{1}$. Giovanna Alessia Sternativo ${ }^{1}$.} Jun-Hwa Cheah ${ }^{2}$. Simone Rollo ${ }^{1}$. Tiziana Marinaci ${ }^{1}$. Claudia Venuleo ${ }^{1}$

\author{
Lucrezia Ferrante \\ lucrezia.ferrante@unisalento.it \\ Giovanna Alessia Sternativo \\ sternativoalessia2@gmail.com \\ Jun-Hwa Cheah \\ jackycheahjh@gmail.com \\ Simone Rollo \\ simone.rollo1@unisalento.it \\ Tiziana Marinaci \\ tiziana.marinaci@unisalento.it \\ Claudia Venuleo \\ claudia.venuleo@unisalento.it
}

1 Department of History, Society and Human Study, University of Salento, Studium 2000, Via Viale San Nicola, 73100 Lecce, Italy

2 School of Business and Economics, Universiti Putra Malaysia, Serdang, Selangor, Malaysia

3 Computer Science and New Technology, WSB University, 80-266 Gdańsk, Poland 